Provided for non-commercial research and education use. Not for reproduction, distribution or commercial use.

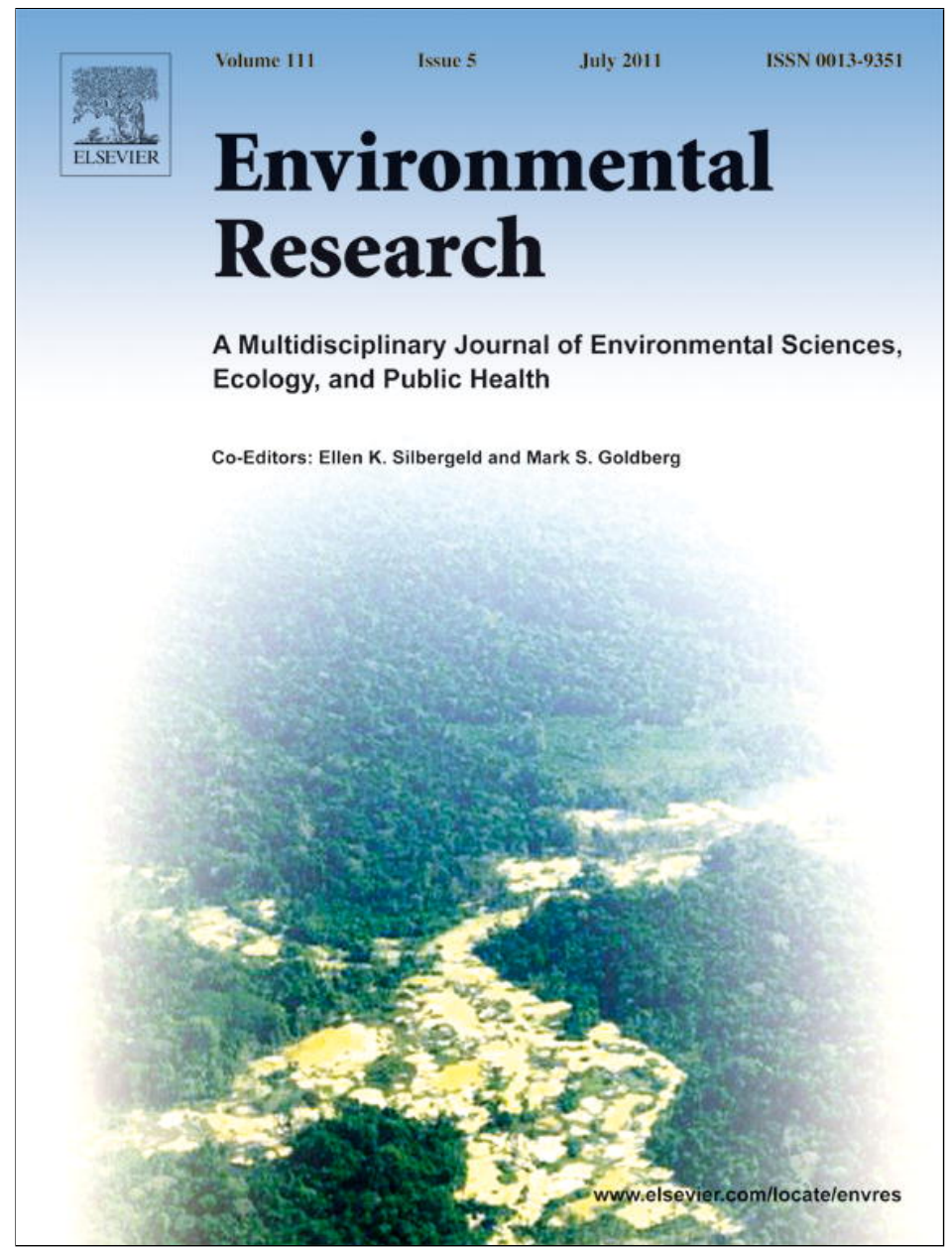

This article appeared in a journal published by Elsevier. The attached copy is furnished to the author for internal non-commercial research and education use, including for instruction at the authors institution and sharing with colleagues.

Other uses, including reproduction and distribution, or selling or licensing copies, or posting to personal, institutional or third party websites are prohibited.

In most cases authors are permitted to post their version of the article (e.g. in Word or Tex form) to their personal website or institutional repository. Authors requiring further information regarding Elsevier's archiving and manuscript policies are encouraged to visit:

http://www.elsevier.com/copyright 


\title{
Human exposure to allergenic pollens: A comparison between urban and rural areas
}

\author{
Floriane Bosch-Cano ${ }^{\mathrm{a}, *}$, Nadine Bernard ${ }^{\mathrm{a}}$, Bertrand Sudre ${ }^{\mathrm{a}}$, François Gillet ${ }^{\mathrm{a}}$, Michel Thibaudon ${ }^{\mathrm{b}}$, \\ Hervé Richard ${ }^{a}$, Pierre-Marie Badot ${ }^{a}$, Pascale Ruffaldi ${ }^{a}$ \\ a Department Chrono-Environment, UMR 6249 CNRS, University of Franche-Comte, 16 route de Gray, 25030 Besançon Cedex, France \\ ${ }^{\mathrm{b}}$ French Network of Aerobiological Monitoring RNSA, Chemin des Gardes - BP 8 - 69610 Saint-Genis-l'Argentière, France
}

\section{A R T I C L E I N F O}

\section{Article history:}

Received 20 August 2010

Received in revised form

24 March 2011

Accepted 4 April 2011

Available online 4 May 2011

Keywords:

Pollens

Allergy

Urban area

Rural area

Aerobiology

\begin{abstract}
A B S T R A C T
Background: Pollinosis is found more frequently in urban areas than in rural environments. This could be partly related to the different types of pollen exposure in these dissimilar areas. The objective of this study was to compare the distribution of pollen in these environments across an urbanization gradient. Methods: Daily pollen abundances were obtained in France using Hirst-type sensors. Sampling was conducted from January to June in 2003 and 2006 in a rural area, a semi-rural area and in two urban areas, which were characterized by several urbanization criteria.

Results: Total allergenic pollen abundance was higher in rural and semi-rural areas than in urban areas irrespective of the sampling year. Multivariate analyses showed that pollen exposures differed according to the type of area and were strongly explained by the urbanization gradient. Grass, ash, birch, alder, hornbeam, hazel and plantain pollen quantities exceeded the allergy threshold more often in rural settings than in urban areas. In urban areas, only plane pollen quantities exceeded the allergy threshold more often than in rural areas.

Conclusions: Allergenic pollen exposure is higher in rural areas than in urban areas, and the most abundant pollen in each area did not originated from the same taxa. This result should be taken into account in epidemiological studies comparing allergies in rural and urban areas to adapt the panel of pollen extracts for human environmental exposure. In addition, this study highlights that some ornamental trees produce a large number of allergenic pollens and provide new sources of aeroallergens.
\end{abstract}

(c) 2011 Elsevier Inc. All rights reserved.

\section{Introduction}

Atmospheric pollution, which is a mixture of gas and mineral or organic particles, is complex and is mainly defined by the negative effect it causes to the environment and human health. In most cases, the chemical and biological components are linked to anthropogenic activities, which are numerous in very populated areas; this is why atmospheric pollutants are most often measured in the European urban areas. The RNSA network (French Network of Aerobiological Monitoring) in France monitors biological pollutants, such as pollens, to estimate future pollen risks in 68 cities (RNSA French Network of Aerobiological Monitoring, 2010). However, monitoring is not conducted in rural areas, even though pollen is the main source of outside allergens in temperate climates (Knox et al., 1997; Behrendt and Becker, 2001;

\footnotetext{
*Corresponding author. Fax: +33381666568.

E-mail addresses: floriane.bosch-cano@univ-fcomte.fr, floriane.bosch-cano@laposte.net (F. Bosch-Cano).
}

Peternel et al., 2003; Traidl-Hoffmann et al., 2009). Obtaining data regarding pollen is necessary because exposure to allergenic pollen is an increasing public health problem in occidental societies where pollinosis has become widespread (D'Amato et al., 2007; Heguy et al., 2008). Some studies have shown that the number of cases of pollinosis in cities is increasing (Behrendt et al., 1992; Heinrich and Wichmann, 2004) and that this disorder occurs more frequently in urban areas than in rural areas (Gonzalo-Garijo et al., 2006; Bousquet et al., 2008). In Greece, children living in urban areas are more sensitive to Poaceae pollen than children in rural areas (Priftis et al., 2007); pollinosis is also more frequent in Spain in urban areas (Armentia et al., 2001). These different levels of prevalence could be linked to the different atmospheric compositions of urban and rural areas.

In the present study, we hypothesized that (1) total allergenic pollen concentration is higher in rural than in urban areas, and (2) the allergenic pollen exposure depends on the degree of urbanization, which can be assessed using the average concentration of a chosen atmospheric pollutant, in this case, nitrogen dioxide $\left(\mathrm{NO}_{2}\right)$. This gas compound is a major indicator of road 
traffic. To test our hypotheses, we investigated allergenic pollen exposure in four areas that differed in their level of urbanization, including a rural, a semi-rural and two urban areas. These observations allowed us to evaluate the quantities of pollen that are inhaled in each type of area.

\section{Materials and methods}

\subsection{Sampling areas}

The concentration of pollen in the atmosphere in Europe is zero from Octobe to January except in the hotter Mediterranean areas (D'Amato et al., 2007). Pollen data were collected in eastern France from January to July in 2003 and 2006 in four areas.

The four areas were characterized according to a set of urbanization criteria and climatic conditions (Table 1). Several parameters can be used to classify areas in rural or urban settings. Here, this classification was based on socio-geographic criteria such as population density (as recommended by the French National Institute for Statistics and Economic Studies (INSEE)), urban unit area, the average number of vehicles per day on the main roads and environmental parameters such as the sources of traffic, industrial pollution and $\mathrm{NO}_{2}$ concentrations near the main roads. The $\mathrm{NO}_{2}$ pollution level is generally higher in cities than in the surrounding areas, and the lowest levels are measured in rural areas (Bernard et al., 1997; Nguyen-Viet et al., 2004). Pollution data were collected using chemiluminescence analyzers (Environment SA), which continuously measured $\mathrm{NO}_{2}$ concentrations during the study period (French air quality monitoring organization with regional ATMO Franche-Comté, COPARLY and AIRPARIF). Meteorological data came from the French national meteorological service (Météo-France (French national meteorological service, 2009)).

The first area, which is located $25 \mathrm{~km}$ west of Besancon, is typically rural. The "Pel-Mon" study site was located in the countryside in two neighboring villages sharing similar characteristics. The study site was located in Pelousey in 2003 and in Montagney in 2006. The second area, Besançon, was a medium-sized city and a semi-rural area. The third and fourth areas were two large cities and typical urban areas, Paris (the capital and the country's largest city) and Lyon (the third largest city and the second largest French agglomeration).

All of these areas have temperate climates that are oceanic or continental. The rural and semi-rural areas are under the double influence of an oceanic and a continental climate. Their botanic environment is half-open landscapes with deciduous forests, pastures and cultures. Lyon has a semi-continental climate with a Mediterranean influence, and Paris has an oceanic climate with a marked continental influence. The surroundings of the urban areas are characterized by semi-natural communities and deciduous forests. Anthropization favors specific vegetation in urban centers, which are mainly composed of trees and weeds with short annual cycles, such as Poaceae and Urticaceae. Ruderal plants such as Plantaginaceae are also abundant and are the first to colonize areas disturbed by roads, buildings and paths (Delarze et al., 1998).

\subsection{Sampling methods}

Seven-day Hirst-type volumetric pollen traps were used for pollen sampling. This trap pumps ten liters of air per minute, which is the average human respiratory flow. Pollen is drawn in through a narrow orifice. Upon impact, pollen grains adhere to sticky tape on a slowly rotating drum, which was collected each week. The tape was then divided into seven sections; each daily segment was transferred to microscope slides, and the pollen grains were counted and identified every $2 \mathrm{~h}$. These bi-hourly results were converted into a daily average of pollen grains per $\mathrm{m}^{3}$ of air. The pollen spectrum obtained with the Hirst-type trap has been shown to characterize the global environment around the sensor (Carinanos et al., 2002; Kasprzyk, 2006) and the pollen exposure (Buters et al., 2010).

Hirst-type traps are designed to record the potential respiration of a human being, which is why the sampler orifice was located $1.50 \mathrm{~m}$ above the ground. Traps were placed under these conditions at our sites, and the sampling area was located in an enclosure to prevent deterioration.

\subsection{Allergenic pollens}

Allergenicity is difficult to define (Traidl-Hoffmann et al., 2009). Pollen allergenic potency depends on the pollen concentration in the air, the quantity of allergens in a grain and the release of these allergens from the pollen; all of these parameters fluctuate according to the species and the year (Bousquet et al., 2008; Buters et al., 2008; Buters et al., 2010). In general, pollen count and allergens in ambient air follow the same temporal trends (Buters et al., 2010). Pollen taxa (i.e., species, genera or families) were categorized according to their allergenic potency, from 0 (none) to 5 (strong) (Thibaudon, 2003). Pollen grains with an allergenic potency greater than or equal to 3 were considered to be allergenic, including the pollen of plane (Platanus) (allergenic potency 3/5) and birch (Betula) (5/5).

The allergenicity threshold is 30 grains $/ \mathrm{m}^{3} /$ day for each arboreal taxon (D'Amato et al., 2007). This common threshold corresponds to the quantity of birch pollen (the most studied pollen) that is necessary to observe early allergy symptoms in the most sensitive patients (Carinanos et al., 2002; Burr et al., 2003). This high airborne pollen level of 30 grains $/ \mathrm{m}^{3} /$ day is considered to be the starting point for allergenic reactions by the Aerobiology Network (Ribeiro et al., 2009; RNSA French Network of Aerobiological Monitoring, 2010). An allergenicity threshold of 10 grains $/ \mathrm{m}^{3} /$ day is commonly used by the RNSA and other authors for herbaceous taxa (D'Amato et al., 1998; D'Amato et al., 2007).

\subsection{Statistical analysis}

To test our first hypothesis (total allergenic pollen concentration is higher in rural than in urban areas), we summed the abundances of all allergenic taxa collected in each area at each year. Total allergenic pollen abundance was compared between rural (including semi-rural) and urban areas using means of a two-sample Welch t-test under the alternative hypothesis of a positive difference for rural sites. In addition, we assessed the year effect using a twosided Welch t-test comparing the 2003 and 2006 samples. The choice of these

Table 1

Characteristics of the four sampling areas from January to July in 2003 and 2006

\begin{tabular}{|c|c|c|c|c|}
\hline \multirow[t]{2}{*}{ Names (geographic coordinates) } & \multirow{2}{*}{$\begin{array}{l}\text { RuRAL AREA } \\
\text { Pel-Mon } 47^{\circ} 17^{\prime} 14^{\prime \prime} \mathrm{N} \\
\left.5^{\circ} 39^{\prime} 43^{\prime \prime} \mathrm{E}\right)\end{array}$} & \multirow{2}{*}{$\begin{array}{l}\text { SEMI-RURAL AREA } \\
\text { Besançon }\left(47^{\circ} 14^{\prime} 35^{\prime \prime} \mathrm{N}\right. \\
\left.\quad 6^{\circ} 01^{\prime} 19^{\prime \prime} \mathrm{E}\right)\end{array}$} & \multicolumn{2}{|l|}{ URBAN AREAS } \\
\hline & & & $\begin{array}{c}\text { Lyon }\left(45^{\circ} 45^{\prime} 35^{\prime \prime} \mathrm{N} 4^{\circ}\right. \\
\left.50^{\prime} 32^{\prime \prime} \mathrm{E}\right)\end{array}$ & $\begin{array}{c}\text { Paris }\left(48^{\circ} 51^{\prime} 24^{\prime \prime} N 2^{\circ} 21^{\prime}\right. \\
\left.03^{\prime \prime} \mathrm{E}\right)\end{array}$ \\
\hline \multicolumn{5}{|l|}{ Urbanization criteria } \\
\hline $\begin{array}{l}\text { Population density in the commune } \\
\left.\text { (individuals } / \mathrm{km}^{2}\right)^{\mathrm{a}}\end{array}$ & 130 & 1800 & 9900 & 25,400 \\
\hline Area of the urban unit $\left(\mathrm{km}^{2}\right)^{\mathrm{a}}$ & 8 & 122 & 950 & 2700 \\
\hline Road traffic (vehicles/day, main road) ${ }^{a}$ & 1000 & 45,000 & 160,000 & 250,000 \\
\hline Main local sources of pollution ${ }^{\mathrm{a}, \mathrm{b}}$ & Zero & Vehicles & Vehicles and industries & Vehicles and industries \\
\hline $\mathrm{NO}_{2}$ concentration $\left(\mu \mathrm{g} \mathrm{m}^{-3}, \text { mean } \pm 1 \mathrm{sd}\right)^{\mathrm{a}, \mathrm{c}, \mathrm{f}}$ & $11.0 \pm 7.9$ & $52.0 \pm 10.0$ & $84.2 \pm 5.4$ & $107.0 \pm 5.6$ \\
\hline Artificialized part (\%) ${ }^{d}$ & 8 & $\overline{47}$ & $9 \overline{3}$ & 98 \\
\hline \multicolumn{5}{|l|}{ Climatic conditions } \\
\hline Altitude $(\mathrm{m})^{\mathrm{a}}$ & $192-313$ & $235-610$ & $162-305$ & $28-130$ \\
\hline Mean daily temperature $\left({ }^{\circ} \mathrm{C}\right){ }^{\mathrm{e}}$ & 10.4 & 10.2 & 11.4 & 12 \\
\hline Mean annual rainfall (mm) ${ }^{\mathrm{e}}$ & 860 & 1100 & 830 & 640 \\
\hline
\end{tabular}

a Cities of Pelousey, Montagney, Besançon, Lyon and, Paris;

b DRIRE: French Regional boards for Industry, Research and Environment;

c ATMO: French air quality monitoring organization with regional ATMO Franche-Comté, COPARLY and AIRPARIF;

d SOeS, French Observation and Statistics Office, and CORINE Land Cover, European data base on land cover;

e Météo-France, French national meteorological service.

${ }^{\mathrm{f}}$ Measurement period: $\mathrm{NO}_{2}$ concentration $\left(\mu \mathrm{g} \mathrm{m}^{-3}\right)$ measured hourly from January to July 2006 . 
parametric tests was made after checking assumptions for normality (ShapiroWilk test, $P>0.1$ ) and homogeneity of variances (Bartlett test, $P>0.1$ ).

To investigate the pattern of pollen assemblages in relation to the gradient of urbanization, we applied a combination of two multivariate analyses to the square-root transformed pollen abundance dataset, in which we included only the 11 allergenic taxa. Square-root transformation improves the distribution of the abundances by decreasing the weight of highly abundant taxa.

First, we performed a hierarchical agglomerative clustering using the Euclidean distance and the Ward method to get a general picture of the similarities among the pollen profiles (Legendre and Legendre, 1998). Hierarchical clustering is a tool for exploratory data analysis that aims at representing discontinuous subsets of objects based on their degree of similarity. Objects are successively grouped into larger and larger clusters to build a tree or dendrogram. In combination with ordination methods, clustering can help reveal the structure of the data (Everitt et al., 2001; Borcard et al., 2011). We used the Euclidean distance to compare pollen profiles so as to preserve the differences in total pollen abundance among sites and years.

To test the predictive power of $\mathrm{NO}_{2}$ as a proxy of the urbanization gradient on the concentration of allergenic pollens from the different taxa (second hypothesis), we performed a partial redundancy analysis (pRDA) using the same squareroot transformed pollen abundance dataset as response matrix, average tropospheric $\mathrm{NO}_{2}$ concentration as the only explanatory variable and sampling year as qualitative covariable. Redundancy analysis (RDA) has become a popular ordination method in numerical ecology (Borcard et al. 2011), which combines multiple regression and principal component analysis (PCA). The first ordination axes are constrained by a set of explanatory variables. Partial RDA displays the patterns of the multivariate response uniquely explained by a linear model of the explanatory variables when the effect of some covariables is held constant. By conditioning the constrained ordination for the year, we removed the year effect in testing the influence of the explanatory variable (Legendre and Legendre, 1998). Therefore, pRDA axis 1 is the only constrained axis of the multivariate regression model, which was tested by 10,000 random permutations.

All statistical analyses were computed using the statistical software $\mathrm{R}$ version 2.12.1 (R Development Core Team, 2010).

\section{Results}

The samples were analyzed by three different specialists. No significant difference between pollen number and pollen species was found among the results of 20 slides that were analyzed independently by the three palynologists (Friedman test and Wilcoxon signed rank test, $P>0.05$ ).

In our study, allergenic pollen concentrations were very low in August and September in three areas during both years. Grass pollen was the most abundant type during this period and had a mean value of $1.6 \pm 0.6$ grains $/ \mathrm{m}^{2} /$ day in August and $1.0 \pm 0.4$ grains $/ \mathrm{m}^{2} /$ day in September. These values are lower than the usual allergenic threshold of 30 grains $/ \mathrm{m}^{2} /$ day for grass (D’Amato et al., 2007). Therefore, these values were not taken into account.

Table 1 shows differences among the four areas. Urbanization criteria, such as population density, urban unit area, road traffic, main sources of pollution, $\mathrm{NO}_{2}$ pollution and artificialized part percentage, exhibit a common pattern: low values in the rural area, intermediate values in the semi-rural area and high values in the urban areas.

Allergenic pollen abundance in the atmosphere ranged from 16,000 to 50,000 grains $/ \mathrm{m}^{3}$ per year (Fig. 1). These allergenic pollen quantities represent $80 \%$ of the total pollen count. No significant difference was observed between 2003 (mean= 33,125) and 2006 (mean $=30,408$ ) (Welch t-test, $P=0.786$ ). In contrast, total allergenic pollen abundance was significantly higher in the rural and semi-rural areas (mean $=41,341)$ than in the typical urban areas (mean $=22,192$ ) (Welch t-test, $P=0.011$ ). However, pollen grains were more abundant in the Lyon urban area in 2003 than in the other urban samples.

An exceptionally high quantity of non-allergenic pollen produced by Urticaceae, represented by nettle (Urtica sp.) in this area, was observed in the rural area in $2006\left(22,300\right.$ grains $\left./ \mathrm{m}^{3}\right)$.

Twenty of the 76 different pollen taxa were observed over 200 times during the 181 days of the study period; these 20 taxa represented $97 \%$ of the total amount. A threshold of 200 observations was selected because, beyond that, pollen grains are present for more than three successive days in a year, which corresponds to the beginning of a pollen season. Eleven of these 20 taxa were considered to be allergenic, which means an allergenic potency $\geq 3 / 5$, including nine arboreal taxa Alnus (alder), Betula (birch), Carpinus (hornbeam), Corylus (hazel), Cupressaceae/Taxaceae (cypress, juniper, thuja, yew), Fraxinus (ash), Platanus (plane), Quercus (oak) and Salix (willow) as well as two herbaceous taxa Poaceae (grass) and Plantago (plantain). The quantities of herbaceous pollen are more important in the rural area than in the other areas; they represent $30 \%$ of the allergenic pollen grains in the rural areas as compared to $10 \%$ in the semi-rural and urban areas.

The cluster analysis of the allergenic pollen data shows a strong separation between rural areas and the other sites (Fig. 2). According to the taxonomic composition, the Lyon urban sample in 2003 is more like the semi-rural area than the other urban samples.

This pattern can be explained by the pRDA multivariate regression model (Fig. 2). The explanatory variable $\mathrm{NO}_{2}$ explains $43.2 \%$ of the variance of the allergenic pollen matrix $(P=0.018)$ after accounting for the year effect, which explains only $9.8 \%$ of the variance. The constrained axis 1 opposes rural sites, where $\mathrm{NO}_{2}$ concentration is very low, to all others, and represents the main urbanization gradient. The principal residual variance expressed by axis 2 corresponds to the second main division of the dendrogram and evidences the difference between two

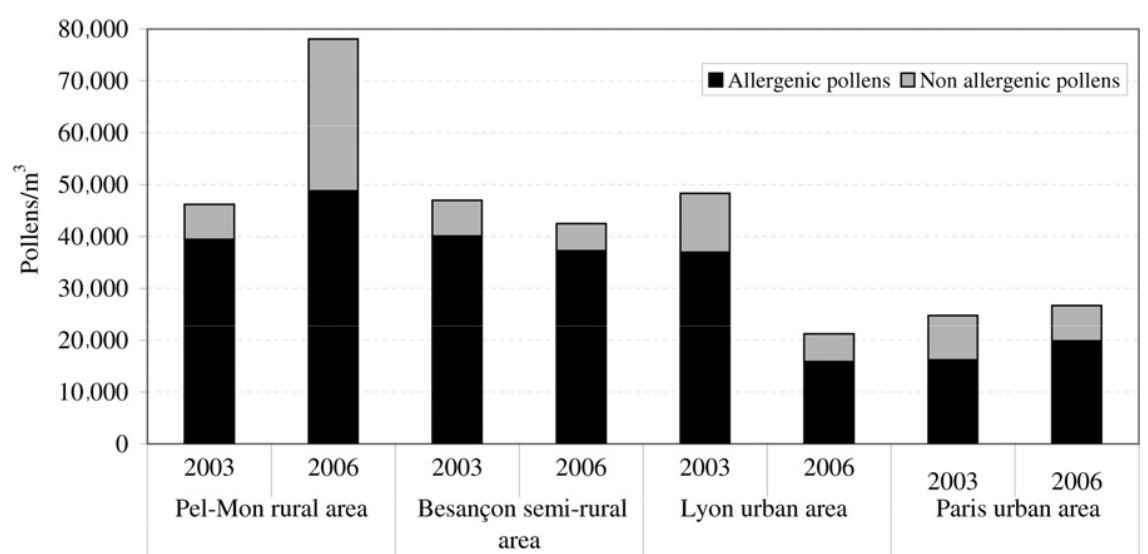

Fig. 1. Total allergenic and non-allergenic airborne pollen abundance recorded at each site and each year. Allergenic pollens (black bars) came from 11 allergenic taxa: nine arboreal taxa, including Alnus (alder), Betula (birch), Carpinus (hornbeam), Corylus (hazel), Cupressaceae/Taxaceae (cypress, juniper, thuja, yew), Fraxinus (ash), Platanus (plane), Quercus (oak) and Salix (willow) as well as two herbaceous taxa, including Poaceae (grass) and Plantago (plantain). Non-allergenic pollens (gray bars) came from 65 other taxa. 
groups of samples: Besançon in 2006 and Lyon in 2003 vs. Lyon in 2006 and Paris in 2003 and in 2006. One sample from the semirural area (Besançon in 2003) occupies an intermediate position along these two gradients.

Rural areas are mainly characterized by a high abundance of Poaceae, Fraxinus and Corylus in the pollen rain, whereas in Besançon in 2006 and Lyon in 2003, Platanus pollen was relatively very abundant (Fig. 2). The abundance of Cupressaceae/Taxaceae appears to be independent of the urbanization gradient because it is strongly correlated to axis 2 but not to axis 1 . Samples from Lyon in 2006 and Paris in both years are distinguished by their low yearly pollen abundance for all allergenic taxa.

The two types of areas, urban and rural, are distinct and differ because of their pollen composition. Table 2 shows the number of

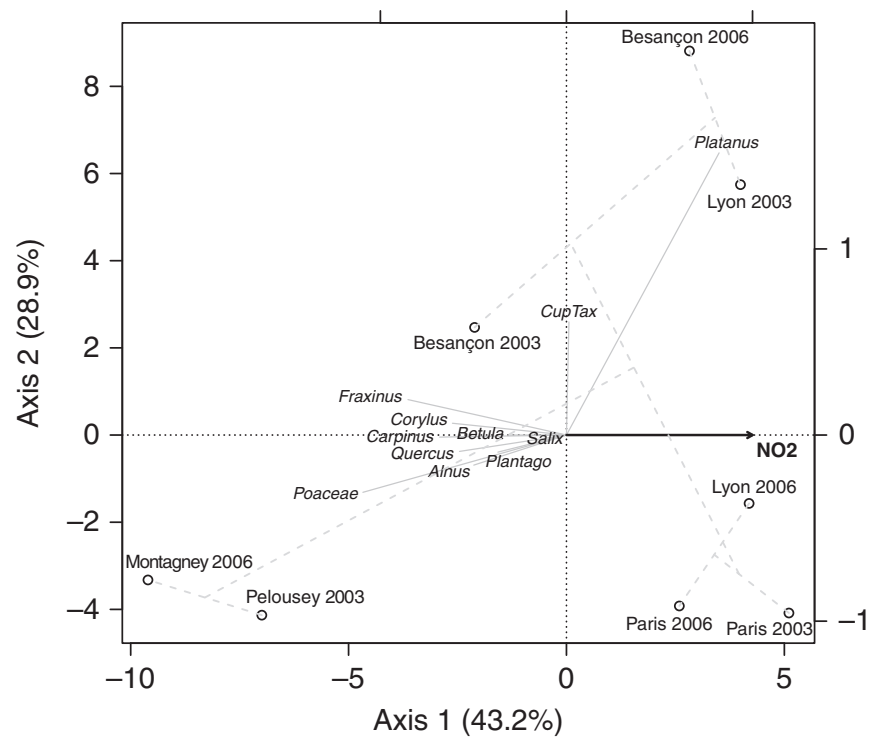

Fig. 2. Partial redundancy analysis triplot of the allergenic pollen taxa with overlaid clustering results. The response variables (gray arrows, italic labels) are square-root transformed abundances of the 11 allergenic pollen taxa, including nine arboreal taxa: Alnus (alder), Betula (birch), Carpinus (hornbeam), Corylus (hazel), Cupressaceae/Taxaceae (cypress, juniper, thuja, yew), Fraxinus (ash), Platanus (plane), Quercus (oak) and Salix (willow) as well as two herbaceous taxa: Poaceae (grass) and Plantago (plantain). $\mathrm{NO}_{2}$ concentration is used as the only explanatory variable (black bold arrow along axis 1), and Year is used as a qualitative covariable. Sites sampled in 2003 or 2006 are represented by points linked by the dendrogram (dashed lines): Pelousey-Montagney (rural area), Besançon (semi-rural area), Lyon and Paris (urban areas). Axis 1 is the constrained axis and axis 2 is the first unconstrained axis. Percentages of variance expressed by each axis are given. days during which the allergenicity threshold was exceeded. This threshold is exceeded more often in the semi-rural and the rural areas than in the urban areas. Moreover, the taxa in the rural and the urban areas that exceed the allergenicity threshold most often were not the same. The threshold is exceeded more often in the semi-rural and the rural areas by the pollen of Fraxinus, Betula, Alnus, Carpinus, Corylus and Plantago. Platanus pollen exceeds the threshold in urban areas more often: 18 days in the urban setting and 15 days in the semi-rural area in contrast to two days in the rural environment.

\section{Discussion}

The results demonstrated that airborne pollen concentrations are higher in rural areas than in urban areas. Pollen taxa also differ in these two types of areas. In addition, we found more allergenic pollen in the semi-rural and the rural areas compared to the urban areas.

\subsection{Pollen counts in rural and urban areas}

Differences between pollen counts in the rural and the urban areas are not only linked to the size of vegetation areas and pollen quantities. Pollen sources are more frequent in rural areas than in typical urban areas, whose surface was more than 93\% artificial in this study (Table 1). Species diversity is low in cities, and the taxa found are specific to the urban environment, which is comprised of weeds and plants with short annual cycles, such as Poaceae (Delarze et al., 1998) and ornamental trees (D'Amato et al., 2007). In our study, tree pollen represented $90 \%$ of the allergenic pollens in the cities and the semi-rural area compared to $70 \%$ in the rural area.

Plane is the only allergenic taxon that is more abundant in the cities than in the rural environment. Plane pollen is quite allergenic (3/5), and the impact of pollinosis on health affects up to $74 \%$ of the allergic patients in Spain (Subiza et al., 1995; Varela et al., 1997; Alcazar et al., 2004; Iglesias et al., 2007), where this tree is among the most abundant species in cities (Varela et al., 1997; Carinanos et al., 2002; Gonzalo-Garijo et al., 2006). Although this taxon is abundantly planted and produces high quantities of pollen, Platanus pollinosis is less studied outside of Spain (Bousquet et al., 1984; Bousquet et al., 2008).

The high allergenic potency of Cupressaceae-Taxaceae pollen $(5 / 5)$ is mainly due to the strong allergenic potency of cypress pollen, which is uncommon in our four study areas. Thuja, yew and juniper are often planted in our study areas. Although these

Table 2

Number of days with a potentially symptomatic quantity of allergenic pollen in the air for each taxon. Allergenicity threshold is 30 grains/ $\mathrm{m}^{3} /$ day for arboreal taxa and 10 grains $/ \mathrm{m}^{3} /$ day for herbaceous taxa.

\begin{tabular}{|c|c|c|c|c|c|c|c|c|}
\hline & \multicolumn{2}{|c|}{ Pel-Mon rural area } & \multicolumn{2}{|c|}{ Besançon semi-rural area } & \multicolumn{2}{|c|}{ Lyon urban area } & \multicolumn{2}{|c|}{ Paris urban area } \\
\hline & 2003 & 2006 & 2003 & 2006 & 2003 & 2006 & 2003 & 2006 \\
\hline \multicolumn{9}{|l|}{ Arboreal taxa } \\
\hline Platanus & 0 & 3 & 15 & 15 & 23 & 17 & 18 & 15 \\
\hline Cupressaceae-Taxaceae & 21 & 10 & 33 & 13 & 28 & 15 & 7 & 21 \\
\hline Corylus & 10 & 19 & 13 & 17 & 0 & 9 & 0 & 18 \\
\hline Alnus & 15 & 20 & 14 & 15 & 7 & 13 & 1 & 17 \\
\hline Carpinus & 10 & 15 & 12 & 10 & 3 & 1 & 0 & 4 \\
\hline Betula & 23 & 24 & 23 & 19 & 15 & 13 & 20 & 24 \\
\hline Fraxinus & 24 & 29 & 33 & 20 & 28 & 21 & 22 & 23 \\
\hline Quercus & 26 & 20 & 24 & 10 & 30 & 20 & 17 & 10 \\
\hline \multicolumn{9}{|l|}{ Herbaceous taxa } \\
\hline Plantago & 17 & 25 & 5 & 0 & 7 & 1 & 0 & 0 \\
\hline Poaceae & 65 & 57 & 51 & 42 & 66 & 41 & 39 & 42 \\
\hline
\end{tabular}


taxa are rarely studied, they are also known to be responsible for pollinosis (Guerin et al., 1996; D’Amato et al., 1998; Alisi et al., 2001; Charpin et al., 2005; Bousquet et al., 2008).

Betulaceae pollen often exceeds the threshold in the semirural and rural areas. This pollen is highly allergenic (5/5), affecting $54 \%$ of the inhabitants in some European countries (D'Amato et al., 2007). Betulaceae pollen is successively produced from January to April and is first produced by hazel, then alder, then hornbeam and eventually birch. Because of the high levels of allergenic cross-reactivity between these pollen grains, Betulaceae pollen can worsen allergy symptoms during the birch-pollen season (Carinanos et al., 2002; D'Amato et al., 2007). The 30 grains $/ \mathrm{m}^{3} /$ day threshold can gradually fall because allergenic potency to birch pollen increases throughout the season; at the beginning, 80 grains $/ \mathrm{m}^{3} /$ day are needed to cause an allergic reaction in sensitive persons. This level decreases to 30 grains/ $\mathrm{m}^{3}$ /day later in the season and is even lower when Betulaceae pollen was previously abundant in the air (Carinanos et al., 2002), which was the case in our study in the semi-rural and rural areas.

Plantain pollen (allergenic potency $3 / 5$ ) is very abundant in rural areas. This herbaceous pollen is involved in up to $53 \%$ of the cases of pollinosis disorders (Subiza et al., 1995; D'Amato et al., 2007). We found 980 plantain pollen grains $/ \mathrm{m}^{3}$ in the rural area, 190 in the semi-rural area and 140 in the urban areas on average per year in our study area. Furthermore, the allergy threshold was exceeded during 21 days in the rural environment compared to less than four days in the other areas (Table 2).

The second and last herbaceous taxon, Poaceae, is classified as a very highly allergenic pollen (5/5) and is involved in roughly $94 \%$ of the cases of pollinosis in European cities (Bousquet et al., 1984; Subiza et al., 1995). The most abundant pollen in this study came from this taxon, and it exceeded the threshold more often in the rural areas. This has already been described in other European studies in which grass pollens were also more abundant in rural areas than in urban ones (Kasprzyk, 2006; Sikoparija et al., 2006). Human exposure could be significant due to the successive flowering of a high number of grass species (Vieira et al., 1998).

\subsection{Use in epidemiology}

This contrast in the distribution of allergenic pollen between different types of areas could modify atopy status in the context of human exposure to allergenic pollens. In epidemiological studies, rural and urban populations have not been exposed to the same pollen patterns (Hesselmar et al., 2001; MajkowskaWojciechowska et al., 2007; Priftis et al., 2007). This may constitute a bias in allergic status assessment. In spite of the correct assessment of some exposure criteria, such as the proximity of animals or parents who smoke, detailed information on human pollen exposure is often incomplete. Furthermore, pollen exposure continues to be problematic for the scientific community when studying allergic diseases. An important question is how one can compare the allergic status of different populations in an epidemiologic study without adapting the pollen skin prick test and IgE panels. The same allergy panel tests are conducted on patients, but the results of the prevalence of allergies in urban and rural areas depend on the pollen taxa tested. The present study shows that pollen exposure is clearly different in rural and urban areas. This must be taken into account to improve estimates of sensitization. For instance, when the definition of an allergy is based on sensitivity to grass pollens, as it was in Priftis and colleagues' study (Priftis et al., 2007), a bias exists because city patients are exposed to grass pollen less often than country patients. The opposite could be true for city patients who are exposed to plane pollen, which is not often included in routine testing in large epidemiological studies. Studies should use panels of antigens adapted to the type of area to estimate the prevalence of sensitization. Allergy testing in epidemiological studies should take into account different types of pollen exposure.

\subsection{Ornamental vegetation}

Although pollen is more abundant in rural areas, the present study shows that allergenic pollen is also present in urban areas despite the lack of grassy areas. Cupressaceae-Taxaceae, Platanus and Betulaceae species are widely used as urban ornamental trees, which constitute an extra risk of causing and worsening allergy symptoms. By planting these types of ornamental vegetation in public areas, urban planning policies could lead to additional exposure to allergic components by providing new sources of aeroallergens (Lorenzoni-Chiesura et al., 2000; Charpin et al., 2005; Gonzalo-Garijo et al., 2006; D'Amato et al., 2007). Urban planners should consider pollen allergenicity as much as other factors to avoid allergies and other related costs. To better understand pollen allergenicity, planners should refer to a list of plants that can be found in the literature (Lorenzoni-Chiesura et al., 2000; Peternel et al., 2003; RNSA French Network of Aerobiological Monitoring, 2010) and avoid planting plane or birch in favor of Prunus, such as plum or other taxa. The literature shows that preventive measures against ornamental pollens are now being implemented (Charpin et al., 2005; Iglesias et al., 2007).

\subsection{Interactions between pollen and air pollutants}

The characterization of the four study sites using the urbanization criteria shows the difference between rural, semi-rural and urban areas. $\mathrm{NO}_{2}$ concentrations are high in urban areas because of traffic and heating. In addition to the risk of allergies linked to pollen exposure as shown in our study, the increase in pollinosis may be related to an increase in air pollutants in urban areas (Priftis et al., 2007). However, it is not yet clear whether hightraffic urban pollution partially enhances sensitization, or if it reduces tolerance to pollens in urban environments. Different atmospheric contaminants, such as $\mathrm{NO}_{2}$, ozone $\left(\mathrm{O}_{3}\right)$ or particulate matter, could increase pollen allergenicity through different mechanisms (Motta et al., 2006; D’Amato et al., 2007; TraidlHoffmann et al., 2009). In spite of the presence of fewer allergenic pollen grains, the urban air could worsen the allergy symptoms of the urban citizen (Bousquet et al., 2008). The potentially increased allergenicity of the combination of pollen and pollutants should be investigated because both elements are present in urban areas. Complementary works, for example, could analyze the effects of plane pollen contaminated with metal trace elements, which are both abundant in cities.

\subsection{Strengths and limitations of the study}

The present results are valid only for studies in a temperate climate, at low altitude and in Europe. However, this work encourages other researchers to study pollen data in different areas and allows for a comparison between rural areas and urban areas. Moreover, our study predicts, for each area, the most useful panel of pollen extracts for allergic sensitivity detection in epidemiological studies. Furthermore, this study demonstrates that some ornamental trees produce abundant amounts of allergenic pollen. Finally, the allergenic pollen exposure is related to the degree of urbanization, which is assessed using the average concentration of nitrogen dioxide. Nitrogen dioxide seems to be a good indicator of degree of urbanization; it is useful for future studies.

Pollen quantities were measured from January to July each year. This study period indicates that there is a lack of data for 
August, which is the Ambrosia pollen season and the end of the Poaceae pollen season. It is difficult to compare the Ambrosia pollen season in different French rural or urban areas because this invasive plant is mainly located around the Lyon area (South-East France, in the Rhone Valley) and is infrequent in rural areas and Paris. However, the main Poaceae pollen season was included in our study because its maximum peak occurs in June (D'Amato et al., 2007).

\section{Conclusions}

Our study showed that allergenic pollen exposure is more important in rural areas than in urban areas, and the most abundant pollen grains do not come from the same species. These conclusions are valid in Europe in areas with similar climatic and environmental characteristics to ours. This result should be taken into account in epidemiological studies that compare allergies in rural and urban areas to adapt the panel of pollen extracts to environmental exposure. The most useful panel for allergic sensitization detection in rural areas should be based on grass, ash, birch, alder, hornbeam, hazel, oak and plantain pollen. A useful panel in urban areas could be based on the pollen from grass, ash, birch, oak and plane. Other tests are beneficial depending on the area, such as those based on cypress pollen in the Mediterranean region. These panels are valuable in targeting the largest population to correctly assess sensitization. In addition, this study highlights that some ornamental trees produce a large number of allergenic pollens, which provide new sources of aeroallergens.

\section{Acknowledgments}

We thank the ADEME Agence De l'Environnement Et de la Maîtrise de l'Energie (French Agency for Environment and Energy Management) and Region of Franche-Comte for their financial support. We thank Atmo-FC, Coparly and Airparif (French Air Quality Monitoring Associations of Besançon, Lyon and Paris, respectively), RNSA Réseau National de Surveillance Aérobiologique (French Network of Aerobiological Monitoring), Météo-France and the Cities of Besançon, Lyon, Paris and Pelousey for granting us permission to use their data. We thank Dorothée Chaillet for her help. We thank Donna L'Hôte and Patricia Alexandre, native English speakers, for their help with grammatical editing.

\section{References}

Alcazar, P., Carinanos, P., De Castro, C., Guerra, F., Moreno, C., Dominguez-Vilches, E., Galan, C., 2004. Airborne plane-tree (Platanus hispanica) pollen distribution in the city of Cordoba, south-western Spain, and possible implications on pollen allergy. J. Invest. Allergol. Clin. Immunol. 14, 238-243.

Alisi, C., Afferni, C., Iacovacci, P., Barletta, B., Tinghino, R., Butteroni, C., Puggioni, E.M., Wilson, I.B., Federico, R., Schinina, M.E., Ariano, R., Di Felice, G., Pini, C. 2001. Rapid isolation, characterization, and glycan analysis of Cup a 1, the major allergen of Arizona cypress (Cupressus arizonica) pollen. Allergy 56, 978-984.

Armentia, A., Banuelos, C., Arranz, M.L., Del Villar, V., Martin-Santos, J.M., Gil, F.J., Vega, J.M., Callejo, A., Paredes, C., 2001. Early introduction of cereals into children's diets as a risk-factor for grass pollen asthma. Clin. Exp. Allergy 31, 1250-1255.

Behrendt, H., Becker, W.M., 2001. Localization, release and bioavailability of pollen allergens: the influence of environmental factors. Curr. Opinion Immunol. 13 709-715.

Behrendt, H., Becker, W.M., Friedrichs, K.H., Darsow, U., Tomingas, R., 1992. Interaction between aeroallergens and airborne particulate matter. Int. Arch. Allergy Immunol. 99, 425-428.

Bernard, N., Astre, C., Vuillot, M., Saintot, M., Gerber, M., 1997. Measurement of background urban nitrogen dioxide pollution levels with passive samplers in Montpellier, France. J. Exp. Sci. Environ. Epidemiol. 7, 165-178.
Borcard, D., Gillet, F., Legendre, P., 2011. Numerical ecology with R, Use R! Series. Springer, New York, USA, p. 302

Bousquet, J., Cour, P., Guerin, B., Michel, F.B., 1984. Allergy in the Mediterranean area. I. Pollen counts and pollinosis of Montpellier. Clin. Allergy 14, 249-258.

Bousquet, J., Khaltaev, N., Cruz, A.A., Denburg, J., Fokkens, W.J., Togias, A., Zuberbier, T., Baena-Cagnani, C.E., Canonica, G.W., van Weel, C., Agache, I., Ait-Khaled, N., Bachert, C., Blaiss, M.S., Bonini, S., Boulet, L.P., Bousquet, P.J. Camargos, P., Carlsen, K.H., Chen, Y., Custovic, A., Dahl, R., Demoly, P., Douagui, H., Durham, S.R., van Wijk, R.G., Kalayci, O., Kaliner, M.A., Kim, Y.Y., Kowalski, M.L., Kuna, P., Le, L.T., Lemiere, C., Li, J., Lockey, R.F., Mavale-Manuel, S., Meltzer, E.O., Mohammad, Y., Mullol, J., Naclerio, R., O'Hehir, R.E., Ohta, K. Ouedraogo, S., Palkonen, S., Papadopoulos, N., Passalacqua, G., Pawankar, R. Popov, T.A., Rabe, K.F., Rosado-Pinto, J., Scadding, G.K., Simons, F.E., Toskala, E., Valovirta, E., van Cauwenberge, P., Wang, D.Y., Wickman, M., Yawn, B.P., Yorgancioglu, A., Yusuf, O.M., Zar, H., Annesi-Maesano, I., Bateman, E.D. Ben Kheder, A., Boakye, D.A. Bouchard, J., Burney, P., Busse, W.W., ChanYeung, M., Chavannes, N.H., Chuchalin, A., Dolen, W.K., Emuzyte, R., Grouse, L., Humbert, M., Jackson, C., Johnston, S.L., Keith, P.K., Kemp, J.P., Klossek, J.M., Larenas-Linnemann, D., Lipworth, B., Malo, J.L., Marshall, G.D., Naspitz, C., Nekam, K., Niggemann, B., Nizankowska-Mogilnicka, E., Okamoto, Y., Orru, M.P., Potter, P., Price, D., Stoloff, S.W., Vandenplas, O., Viegi, G., Williams, D. 2008. Allergic Rhinitis and its Impact on Asthma (ARIA) 2008 update (in collaboration with the World Health Organization, GA(2)LEN and AllerGen). Allergy 63, 8-160.

Burr, M.L., Emberlin, J.C., Treu, R., Cheng, S., Pearce, N.E., 2003. Pollen counts in relation to the prevalence of allergic rhinoconjunctivitis, asthma and atopic eczema in the International Study of Asthma and Allergies in Childhood (ISAAC). Clin. Exp. Allergy 33, 1675-1680.

Buters, J.T., Kasche, A., Weichenmeier, I., Schober, W., Klaus, S., Traidl-Hoffmann, C., Menzel, A., Huss-Marp, J., Kramer, U., Behrendt, H., 2008. Year-to-year variation in release of Bet $\mathrm{v} 1$ allergen from birch pollen: evidence for geographical differences between West and South Germany. Int. Arch. Allergy Immunol. 145, 122-130.

Buters, J.T., Weichenmeier, I., Ochs, S., Pusch, G., Kreyling, W., Boere, A.J., Schober W., Behrendt, H., 2010. The allergen Bet v 1 in fractions of ambient air deviates from birch pollen counts. Allergy 65, 850-858.

Carinanos, P., Alcazar, P., Galan, C., Dominguez, E., 2002. Privet pollen (Ligustrum sp.) as potential cause of pollinosis in the city of Cordoba, south-west Spain. Allergy 57, 92-97.

Charpin, D., Calleja, M., Lahoz, C., Pichot, C., Waisel, Y., 2005. Allergy to cypress pollen. Allergy 60, 293-301.

D’Amato, G., Cecchi, L., Bonini, S., Nunes, C., Annesi-Maesano, I., Behrendt, H., Liccardi, G., Popov, T., van Cauwenberge, P., 2007. Allergenic pollen and pollen allergy in Europe. Allergy 62, 976-990.

D’Amato, G., Spieksma, F.T., Liccardi, G., Jager, S., Russo, M., Kontou-Fili, K., Nikkels, H., Wuthrich, B., Bonini, S., 1998. Pollen-related allergy in Europe. Allergy 53, 567-578.

Delarze, R., Gonseth, Y., Galland, P., 1998. Guide des milieux naturels de Suisse: écologie, menaces, espèces caractéristiques. Delachaux et Niestlé, Lausanne.

Everitt, B., Landau, S., Leese, M., 2001. Cluster Analysis, 4th ed. Wiley 237 p.

Gonzalo-Garijo, M.A., Tormo-Molina, R., Muñoz-Rodríguez, A.F., Silva-Palacios, I., 2006. Differences in the spatial distribution of airborne pollen concentrations at different urban locations within a city. J. Invest. Allergol. Clin. Immunol. 16 , 37-43.

Guerin, B., Kanny, G., Terrasse, G., Guyot, J.L., Moneret-Vautrin, D.A., 1996. Allergic rhinitis to thuja pollen. Int. Arch. Allergy. Immunol. 110, 91-94.

Heguy, L., Garneau, M., Goldberg, M.S., Raphoz, M., Guay, F., Valois, M.F., 2008. Associations between grass and weed pollen and emergency department visits for asthma among children in Montreal. Environ. Res. 106, 203-211.

Heinrich, J., Wichmann, H.E., 2004. Traffic related pollutants in Europe and their effect on allergic disease. Curr. Opinion Allergy Clin. Immunol. 4, 341-348.

Hesselmar, B., Aberg, B., Eriksson, B., Aberg, N., 2001. Allergic rhinoconjunctivitis, eczema, and sensitization in two areas with differing climates. Pediatr. Allergy Immunol. 12, 208-215.

Iglesias, I., Rodriguez-Rajo, F.J., Mendez, J., 2007. Behavior of Platanus hispanica pollen, an important spring aeroallergen in northwestern Spain. J. Invest Allergol. Clin. Immunol. 17, 145-156.

Kasprzyk, I., 2006. Comparative study of seasonal and intradiurnal variation of airborne herbaceous pollen in urban and rural areas. Aerobiologia 22, 185-195.

Knox, R.B., Suphioglu, C., Taylor, P., Desai, R., Watson, H.C., Peng, J.L., Bursill, L.A. 1997. Major grass pollen allergen Lol p 1 binds to diesel exhaust particles: implications for asthma and air pollution. Clin. Exp. Allergy 27, 246-251.

Legendre, P., Legendre, L., 1998. Numerical Ecology, 2nd ed. Elsevier Science 870 p.

Lorenzoni-Chiesura, F., Giorato, M., Marcer, G., 2000. Allergy to pollen of urban cultivated plants. Aerobiologia 16, 313-316.

Majkowska-Wojciechowska, B., Pelka, J., Korzon, L., Kozlowska, A., Kaczala, M. Jarzebska, M., Gwardys, T., Kowalski, M.L., 2007. Prevalence of allergy, patterns of allergic sensitization and allergy risk factors in rural and urban children. Allergy 62, 1044-1050.

Météo-France (French national meteorological service), Weather forecasting. 2009.

Motta, A.C., Marliere, M., Peltre, G., Sterenberg, P.A., Lacroix, G., 2006. Trafficrelated air pollutants induce the release of allergen-containing cytoplasmic granules from grass pollen. Int. Arch. Allergy Immunol. 139, 294-298. 
Nguyen-Viet, H., Gilbert, D., Bernard, N., Mitchell, E.A.D., Badot, P.-M., 2004. Relationship between atmospheric pollution characterized by $\mathrm{NO}_{2}$ concentrations and testate amoebae density and diversity. Acta Protozool. 43, 233-239.

Peternel, R., Culig, J., Mitic, B., Vukusic, I., Sostar, Z., 2003. Analysis of airborne pollen concentrations in Zagreb, Croatia, 2002. Ann. Agric. Environ. Med. 10, 107-112.

Priftis, K.N., Anthracopoulos, M.B., Nikolaou-Papanagiotou, A., Matziou, V., Paliatsos, A.G., Tzavelas, G., Nicolaidou, P., Mantzouranis, E., 2007. Increased sensitization in urban vs. rural environment-rural protection or an urban living effect? Pediatr. Allergy Immunol. 18, 209-216.

R Development Core Team, 2010. R: A Language and Environment for Statistical Computing. R Foundation for Statistical Computing. Vienna, Austria $<\mathrm{http}$ :/ www.R-project.org/ > . Accessed on: 2010/11/15.

Ribeiro, H., Oliveira, M., Ribeiro, N., Cruz, A., Ferreira, A., Machado, H., Reis, A., Abreu, I., 2009. Pollen allergenic potential nature of some trees species: a multidisciplinary approach using aerobiological, immunochemical and hospital admissions data. Environ. Res. 109, 328-333.

RNSA French Network of Aerobiological Monitoring, 2010. Pollen Allergies, $\langle$ www.pollens.fr 〉, last accessed on 2010/07/01.
Sikoparija, B., Radisic, P., Pejak, T., Simic, S., 2006. Airborne grass and ragweed pollen in the southern Panonnian Valley-consideration of rural and urban environment. Ann. Agric. Environ. Med. 13, 263-266.

Subiza, J., Jerez, M., Jimenez, J.A., Narganes, M.J., Cabrera, M., Varela, S., Subiza, E., 1995. Allergenic pollen pollinosis in Madrid. J. Allergy Clin. Immunol. 96, $15-23$.

Thibaudon, M., 2003. The allergy risk associated with pollens in France. Eur. Ann. Allergy Clin. Immunol. 35, 170-172.

Traidl-Hoffmann, C., Jakob, T., Behrendt, H., 2009. Determinants of allergenicity. J. Allergy Clin. Immunol. 123, 558-566.

Varela, S., Subiza, J., Subiza, J.L., Rodriguez, R., Garcia, B., Jerez, M., Jimenez, J.A., Panzani, R., 1997. Platanus pollen as an important cause of pollinosis. J. Allergy Clin. Immunol. 100, 748-754.

Vieira, F.A., Ferreira, E.N., Cruz, A.A., 1998. Grass allergy increases the risk of tree pollen sensitization: a warning to urban planners. J. Allergy Clin. Immunol. 102, 700-701. 